\title{
Prevalence of Anemia and Its Associate Factors among Women of Reproductive Age in Lao PDR: Evidence from a Nationally Representative Survey
}

\author{
Sengtavanh Keokenchanh $\mathbb{D}^{1,2}$ Sengchanh Kounnavong, ${ }^{3}$ Akiko Tokinobu, ${ }^{4}$ \\ Kaoru Midorikawa, ${ }^{5}$ Wakaha Ikeda, ${ }^{6}$ Akemi Morita, ${ }^{1}$ Takumi Kitajima, ${ }^{1}$ \\ and Shigeru Sokejima ${ }^{1,6}$ \\ ${ }^{1}$ Department of Public Health and Occupational Medicine, Mie University Graduate School of Medicine, 2-174 Edobashi, \\ Tsu-Shi, Mie 514-8507, Japan \\ ${ }^{2}$ Foreign Relation Division, Cabinet of the Ministry of Health, Rue Simeuang, Ban Thatkhao, Sisattanack District, \\ Vientiane Capital, Laos \\ ${ }^{3}$ Lao Tropical and Public Health Institute, Ministry of Health, Samsenthai Road, Ban Kaognot, Sisattanack District, \\ Vientiane Capital, Laos \\ ${ }^{4}$ Department of Epidemiology and Preventive Medicine, Ehime University Graduate School of Medicine, 454 Shitsukawa, \\ Toon-shi, Ehime 791-0295, Japan \\ ${ }^{5}$ Faculty of Child Education, Suzuka University, 663-222 Koriyama-Cho, Suzuka-Shi, Mie 510-0298, Japan \\ ${ }^{6}$ Epidemiology Centre for Disease Control and Prevention, Mie University Hospital, 2-174 Edobashi, Tsu-Shi, Mie 514-8507, \\ Japan
}

Correspondence should be addressed to Sengtavanh Keokenchanh; keokenchanh.sengtavanh@gmail.com

Received 6 September 2020; Revised 24 December 2020; Accepted 30 December 2020; Published 15 January 2021

Academic Editor: Gunanidhi Dhangadamajhi

Copyright (C) 2021 Sengtavanh Keokenchanh et al. This is an open access article distributed under the Creative Commons Attribution License, which permits unrestricted use, distribution, and reproduction in any medium, provided the original work is properly cited.

Introduction. Anemia continues to be a major public health problem significant among women of reproductive age (WRA) in developing countries, including Lao People's Democratic Republic (Lao PDR), where the prevalence of anemia among women remains high. This study aimed to assess the prevalence of anemia and its associated factors among WRA 15-49 years in Lao PDR. Methods. We conducted a cross-sectional study, using the Lao Social Indicator Survey II, 2017 dataset. A total of 12,519 WRA tested for anemia were included in this study, through multistage sampling approaches. Binary logistic regression was used to determine the associated factors of anemia. Results. Of 12,519 women, 4,907 (39.2\%) were anemic. Multivariate logistic regression revealed that living in central provinces (aOR: 2.16, 95\% CI: 1.96-2.38), rural area (aOR: 1.1, 95\% CI: 1.00-1.20), large family size with more than 6 persons (aOR: 1.14, 95\% CI: 1.01-1.29), pregnancy (aOR: 1.46, 95\% CI: 1.22-1.74), having any adverse pregnancy outcomes (aOR: 1.14, 95\% CI: 1.03-1.25), poor drinking water (aOR: 1.24, 95\% CI: 1.10-1.39), and poor sanitation facility (aOR: 1.15, 95\% CI: 1.03-1.28) were significantly associated with an increased risk of anemia. Conversely, four factors were associated with anemia preventively, including being aged 25-34 years (aOR: 0.81, 95\% CI: $0.74-0.90$ ), postsecondary education (aOR: 0.76 , 95\% CI: 0.60-0.97), Hmong-Mien ethnicity (aOR: 0.48, 95\% CI: 0.39-0.59), and watching television almost daily (aOR: 0.84, 95\% CI: 0.75-0.95). Conclusion. Anemia continues to be a major public health challenge in Lao PDR. Interventions should be considered on geographic variations, improving safe water and sanitation facility, promoting of iron supplements during pregnancy, and health education through mass media for women in rural areas. 


\section{Introduction}

Anemia is a condition of red blood cells insufficient to meet the body's physiological demands. According to the World Health Organization (WHO), the threshold hemoglobin $(\mathrm{Hb})$ level for anemia is less than $120 \mathrm{~g} / \mathrm{l}$ for nonpregnant women and $110 \mathrm{~g} / \mathrm{l}$ for pregnant women aged 15 years and above [1]. Anemia is a global public health problem, with major consequences for human health as well as adverse impacts on social and economic development [2]. The WHO estimates two billion anemic persons and anemia is responsible for one million deaths a year, and about threequarters of cases occur in Africa and Southeast Asia [3]. The global prevalence of anemia in pregnant and nonpregnant women was $38 \%$ and $29 \%$, respectively, in 2011, translated to about half a million anemic nonpregnant women and 32 million anemic pregnant women. Worldwide, $50 \%$ of anemia cases are caused by iron deficiency, and other important causes, including infections, nutritional deficiencies, and genetic conditions [4].

Several studies had found various factors associated to increase the risk of developing anemia in women of reproductive age (WRA) [5-7] such as consumption of wells water as the sources of drinking water, having permanent sterilization, living in small and medium-sized cities, aged between 30-39 years, no or occasional smoking, spring and winter seasons, ethnicity, and having low education level. Moreover, older age, limited knowledge of anemia, pregnancy during the second and third trimesters, multiparity, and experience of abortions were more likely reasons of anemia in pregnant women and lactating women $[5,8-10]$.

Anemia is a crucial public health problem in Lao People's Democratic Republic (Lao PDR). Although the prevalence of anemia among pregnant and nonpregnant women was reduced from $56.5 \%$ to $36.0 \%$ and from $46.1 \%$ to $31.0 \%$ in 2006 and 2011, respectively [2, 11], it remained higher than the global average (29\%) for nonpregnant women [12]. The improvement of anemia in the country might have been attributed to the program for intermittent iron and folic acid supplementation that targeted women of childbearing age [13]. However, there are few studies on anemia that have been conducted in Lao PDR, mostly focusing on preschool children [14] and adolescent women [15], and all of them were carried out on a small scale and limited to a specific region of the country. Moreover, the associated factors for the prevalence of anemia in WRA have not been investigated. Therefore, this study aimed to assess the prevalence of anemia and to identify its associated risk factors among WRA $15-49$ years in Lao PDR.

\section{Materials and Methods}

2.1. Study Design and Data Sources. We used the data from the Lao Social Indicator Survey (LSIS) II, 2017, a nationally representative cross-sectional survey conducted in July to November 2017 by the Lao Statistic Bureau in collaboration with the Ministry of Health and the Ministry of Education and Sport, as part of the Global Multiple Indicator Cluster Survey (MICS) Program developed by the United Nations
Children's Fund (UNICEF). It combines the MICS and the Demographic and Health Survey (DSH).

2.2. Sampling and Study Population. LSIS II used the multistage, stratified cluster sampling approach for the selection of the survey sample. The sampling frame for this survey consisted of a list of all villages, considered as enumeration areas (EAs) in the country. The version used as the sampling frame was the village register of December 2015. They were stratified by the type of residence (urban, rural with the road, and rural without road areas) in every 18 provinces, defined as sampling strata. A two-stage sampling unit was used to ensure that estimates were representative at the national level. At the first stage, 1,170 EAs ( 373 from urban areas, 687 from rural with road areas, and 110 from rural without road areas) were selected from each sampling strata by using systematic probability proportional to size sampling procedures. At the second stage, 20 households were randomly selected from each EA, resulting in a total of 23,400 households; more details were described elsewhere [16]. Anemia was tested for in WRA 15-49 years in half of the selected households from the general survey. On-site hemoglobin analysis was performed by using a battery-operated portable HemoCue analyzer to estimate the $\mathrm{Hb}$ level in grams per deciliter blood. WRA 15-49 years who were tested for $\mathrm{Hb}$ and had the result of anemia testing were included in this study The LSIS II data were collected based on the MICS6 model questionnaire by qualified and trained interviewers. Details of the questionnaires can be found in the report of LSIS II, 2017 [16].

2.3. Study Variables. The outcome variable was the presence of anemia during the survey, which is defined as $\mathrm{Hb}$ level below $11.0 \mathrm{~g} / \mathrm{dl}$ and $12.0 \mathrm{~g} / \mathrm{dl}$ for pregnant and nonpregnant women, respectively, in accordance with WH [1]. The independent variables included in the analysis were identified based on previous literature, including individual characteristics such as age, level of education, ethnolinguistic group, religion, health insurance coverage, marital status, pregnancy status (pregnant versus nonpregnant), and experience of adverse pregnancy outcomes for the last pregnancy; environmental and health-related factors, including exposure to mass media: reading newspapers/magazine, listening to radio, and watching television (TV); main sources of drinking water, type of toilet facility, tobacco/ cigarette smoking, and alcohol drinking; and household factors such as the area of residence (urban, rural with road, and rural without road), the region of residence (northern, central, and southern provinces), household wealth status, and size of the family.

2.4. Data Analyses. We summarized anemia status in accordance with each independent variable by conducting descriptive statistics analyses. Pearson's chi-squared test was used to assess the association between anemia status and independent variables. A variable found statistically 
significant in bivariate analyses with $p$-values $<0.05$ was further analyzed in multivariate analysis, after checking for multicollinearity by examining the variance inflation factors (VIF), and only variables with VIF less than 2 were included. Binary logistic regression was performed to determine the associated factors of anemia among WRA. The results of univariate and multivariate logistic regression analyses were reported in crude odds ratio (OR) and adjusted odds ratio (aOR) with 95\% confidence intervals (CI), respectively. Women's sampling weights were available in the dataset and were included in all analyses for adjusting the effects of the stratified cluster sampling approach. All data were analyzed on SPSS, version 25 (IBM Corp., Armonk, NY).

2.5. Ethics Statement. The study protocol was reviewed and approved by the National Ethics Committee for Health Research, the Ministry of Health, Lao PDR (ID: 2020.33.NW). Verbal consent was obtained for each respondent participating prior to the data collection and each participant was informed of the voluntary nature of participation and the confidentiality and anonymity of information.

\section{Results}

3.1. Characteristics of Study Population and Prevalence of Anemia. A total of 12,519 WRA 15-49 years were included in this study. The mean age of the participant was 30.1 $( \pm 9.76)$ years. Around $35.1 \%$ of women had primary education and were living in the richest households (23.2\%), with more than 6 people (24.5\%). More than half of the women were Lao-Tai $(65.1 \%)$, were married $(73 \%)$, resided in rural with road area (57\%), and had improved source of drinking water $(85.9 \%)$ and improved sanitation facility (77.9\%) (Table 1).

An overall prevalence of anemia among WRA15-49 years was $39.2 \%$ (95\% CI, 38.3\%-40\%). The prevalence of anemia was particularly high among women who resided in the southern provinces $(45.4 \%)$, were uneducated $(42.3 \%)$, were married $(43.6 \%)$, were pregnant $(47.3 \%)$, experienced any adverse pregnancy outcomes (43\%), ever smoked (42.1\%), and had not watched TV at all (42\%) (Table 1).

3.2. Associate Factors of Anemia. Multivariate analyses highlighted that women living in central provinces $(\mathrm{aOR}$ 2.16; 95\% CI 1.96-2.38), southern provinces (aOR 2.05; 95\% CI 1.82-2.31), and a rural area with the road (aOR 1.10; 95\% CI 1.0-1.20) and with large family size with more than 6 people (aOR 1.14; 95\% CI 1.01-1.29) were significantly associated with an increased risk of developing anemia as compared to those living in northern provinces and urban areas and with less than 4 household members, respectively. Similarly, pregnant women (aOR 1.46; 95\% CI 1.22-1.74) and women who experienced any adverse pregnancy outcomes (aOR 1.14; 95\% CI 1.03-1.25) had higher odds of developing anemia compared to their counterparts. In addition, increased odds of developing anemia were found among women who had an unimproved source of drinking water (aOR 1.24; 95\% CI 1.10-1.39) and unimproved toilet facility (aOR 1.15; 95\% CI 1.03-1.28). Conversely, compared to women aged $15-24$ years, women aged $25-34$ years (aOR $0.81 ; 95 \%$ CI $0.74-0.90$ ) were negatively associated with developing anemia. Similarly, a low risk of anemia was found among women who had postsecondary education (aOR 0.76 ; 95\% CI 0.60-0.97), belonged to Hmong-Mien ethnicity (aOR 0.48; 95\% CI 0.39-0.59), and watched television almost daily (aOR 0.84 ; 95\% CI $0.75-0.95$ ) (Table 2).

\section{Discussion}

This study aims to assess the prevalence of anemia and to comprehend the influence of various factors, including individual characteristics and environmental and household factors on the prevalence of anemia among WRA 15-59 years in Lao PDR and to therefore identify its associated risk factors. This study revealed the prevalence of anemia among WRA remained high (39.2\%). However, the prevalence of anemia among Lao women was lower than many other countries in the same region $[17,18]$, as well as developing countries on average [19]. However, it is still considered as a public health problem significant particularly among pregnant women as severe public health concerns, according to WHO classification [1]. Various associate factors for the prevalence of anemia were found after controlling for available independent variables.

At the individual level, we found that women who had any adverse pregnancy outcomes have higher odds of developing anemia. It is well documented that maternal anemia leads to poor neonatal outcomes such as low birth weight, stillbirth, preterm delivery, and early neonate death [20], women who had abortion reported a higher risk of developing anemia $[8,21]$. Also, this might be due to iron deficiency $[20,22]$. In Lao PDR, pregnant women usually receive iron supplementation during their antenatal care (ANC) visits. However, ANC visit rate in Lao PDR was increased from $35 \%$ to $54 \%$ in 2006 and 2011, respectively, but only half of those women took iron pills during their pregnancy [23]. Moreover, a high prevalence of insufficient iron intake (91\%) was reported in a recent study [24]. In addition, current pregnancy shows an increased odd of anemia, this finding was found in other different settings [25-27]. Physiologically, the plasma volume increases progressively during pregnancy, causing a two-to three-fold and 10- to 20-fold increase in the requirement for iron and folate, respectively. For these reasons, the intake of iron and folic acid supplementation is necessary to maintain $\mathrm{Hb}$ at normal levels [28]. Therefore, interventions should highlight the promotion of iron and other micronutrient supplements during pregnancy.

On the other hand, our study found that women aged 25-34 had a lower risk of being anemic than those of younger ages. A similar finding was found in India [9]. As $60 \%$ of Lao people are younger than 25 years and early-age married, that resulted in early childbearing being very common among young women, with high birth rates at 15-19 years [29]. Women younger than 18 years had received less ANC visits [30]; consequently, this could be mean 
TABLE 1: Sociodemographic characteristics and prevalence of anemia among WRA in Lao PDR.

\begin{tabular}{|c|c|c|c|c|}
\hline Characteristics & $\begin{array}{c}\text { Total } \\
\text { (weighted) }\end{array}$ & $\begin{array}{c}\text { Nonanemia } \\
n(\%)\end{array}$ & $\begin{array}{c}\text { Anemia } \\
n(\%)\end{array}$ & $p$-value \\
\hline Age, years & & 12519 & & \multirow{4}{*}{$<0.001$} \\
\hline $15-24$ & $4285(34.2)$ & $2539(59.3)$ & $1746(40.7)$ & \\
\hline $25-34$ & $3911(31.2)$ & $2490(63.7)$ & $1421(36.3)$ & \\
\hline $35-49$ & $4323(34.5)$ & $2587(59.8)$ & $1736(40.2)$ & \\
\hline Education & & 12519 & & \multirow{7}{*}{0.02} \\
\hline None & $1996(15.9)$ & $1151(57.7)$ & $845(42.3)$ & \\
\hline Primary & $4391(35.1)$ & $2696(61.4)$ & $1695(38.6)$ & \\
\hline Lower secondary & $2726(21.8)$ & $1661(60.9)$ & $1065(39.1)$ & \\
\hline Upper secondary & $1750(14)$ & $1067(61)$ & $683(39)$ & \\
\hline Postsecondary/nontertiary & $418(3.3)$ & $272(65.1)$ & $146(34.9)$ & \\
\hline Tertiary & $1238(9.9)$ & $770(62.2)$ & $468(37.8)$ & \\
\hline Ethnolinguistic group & & 12518 & & \multirow{6}{*}{$<0.001$} \\
\hline Lao-Tai & $8154(65.1)$ & $4843(59.4)$ & $3311(40.6)$ & \\
\hline Mon-Khmer & $2878(23)$ & $1729(60.1)$ & $1149(39.9)$ & \\
\hline Hmong-Mien & $1061(8.5)$ & $780(73.5)$ & $281(26.5)$ & \\
\hline Chinese-Tibetan & $307(2.5)$ & $198(64.5)$ & $109(35.5)$ & \\
\hline Other & $118(0.9)$ & $65(55.1)$ & $53(44.9)$ & \\
\hline Religion & & 12518 & & \multirow{5}{*}{$<0.001$} \\
\hline Buddhist & $8404(67.1)$ & $4993(59.4)$ & $3411(40.6)$ & \\
\hline Animist & $3904(31.2)$ & $2501(64.1)$ & $1403(35.9)$ & \\
\hline Christian & $186(1.5)$ & $108(58.1)$ & $78(41.9)$ & \\
\hline Other & $24(0.2)$ & $13(54.2)$ & $11(45.8)$ & \\
\hline Area of residence & & 12519 & & \multirow{4}{*}{$<0.001$} \\
\hline Urban & $4202(33.6)$ & $2646(63)$ & $1556(37)$ & \\
\hline Rural with road & $7140(57)$ & $4207(58.9)$ & $2933(41.1)$ & \\
\hline Rural without road & $1177(9.4)$ & $763(64.8)$ & $414(35.2)$ & \\
\hline Region of residence & & 12519 & & \multirow{4}{*}{$<0.001$} \\
\hline Northern provinces & $3887(31)$ & $2842(73.1)$ & $1045(26.9)$ & \\
\hline Central provinces & $6253(49.9)$ & $3474(55.6)$ & $2779(44.4)$ & \\
\hline Southern provinces & $2379(19)$ & $1299(54.6)$ & $1080(45.4)$ & \\
\hline Wealth quintiles & & 12519 & & \multirow{6}{*}{0.36} \\
\hline Poorest & $2145(17.1)$ & $1268(59.1)$ & $877(40.9)$ & \\
\hline Poorer & $2272(18.1)$ & $1381(60.8)$ & $891(39.2)$ & \\
\hline Middle & $2414(19.3)$ & $1474(61.1)$ & $940(38.9)$ & \\
\hline Richer & $2785(22.2)$ & $1727(62)$ & $1058(38)$ & \\
\hline Richest & $2903(23.2)$ & $1766(60.8)$ & $1137(39.2)$ & \\
\hline Size of family & & 12517 & & \multirow{4}{*}{0.01} \\
\hline$\leq 3$ persons & $2040(16.3)$ & $1279(62.7)$ & $761(37.3)$ & \\
\hline $4-6$ persons & $7409(59.2)$ & $4529(61.1)$ & $2880(38.9)$ & \\
\hline$>6$ persons & $3068(24.5)$ & $1807(58.9)$ & $1261(41.1)$ & \\
\hline Source of drinking water & & 12519 & & \multirow{3}{*}{$<0.001$} \\
\hline Improved & $10760(85.9)$ & $6660(61.9)$ & $4100(38.1)$ & \\
\hline Unimproved & $1759(14.1)$ & $956(54.3)$ & $803(45.7)$ & \\
\hline Type of toilet facility & & 12518 & & \multirow{3}{*}{$<0.001$} \\
\hline Improved & $9752(77.9)$ & $6094(62.5)$ & $3658(37.5)$ & \\
\hline Unimproved & $2766(22.1)$ & $1521(55)$ & $1254(45)$ & \\
\hline Health insurance status & & 12518 & & \multirow{3}{*}{0.06} \\
\hline Uninsured & $10640(85)$ & $6436(60.5)$ & $4204(39.5)$ & \\
\hline Insured & $1878(15)$ & $1179(62.8)$ & $699(37.2)$ & \\
\hline Marital status & & 12519 & & \multirow{4}{*}{0.07} \\
\hline Never married & $2826(22.6)$ & $1738(61.5)$ & $1088(38.5)$ & \\
\hline Currently married & $9145(73)$ & $5569(60.9)$ & $3576(39.1)$ & \\
\hline Formerly married & $548(4.4)$ & $309(56.4)$ & $239(43.6)$ & \\
\hline Pregnancy status & & 12519 & & \multirow{3}{*}{$<0.001$} \\
\hline None & $11961(95.5)$ & $7322(61.2)$ & $4639(38.8)$ & \\
\hline Currently pregnant & $558(4.5)$ & $294(52.7)$ & $264(47.3)$ & \\
\hline
\end{tabular}


TABLE 1: Continued.

\begin{tabular}{|c|c|c|c|c|}
\hline Characteristics & $\begin{array}{c}\text { Total } \\
\text { (weighted) }\end{array}$ & $\begin{array}{c}\text { Nonanemia } \\
n(\%)\end{array}$ & $\begin{array}{c}\text { Anemia } \\
n(\%)\end{array}$ & $p$-value \\
\hline Adverse pregnancy outcomes & & 12519 & & \multirow{3}{*}{$<0.001$} \\
\hline No (live births) & $10158(81.1)$ & $6261(61.6)$ & $3897(38.4)$ & \\
\hline Yes (stillbirths, miscarriage, abortion) & $2361(18.9)$ & $1355(57.4)$ & $1006(42.6)$ & \\
\hline Reading newspaper/magazine & & 12518 & & \multirow{5}{*}{0.13} \\
\hline None & $10613(84.8)$ & $6420(60.5)$ & $4193(39.5)$ & \\
\hline Less than once a week & $976(7.8)$ & $607(62.2)$ & $369(37.8)$ & \\
\hline At least once a week & $718(5.7)$ & $463(64.5)$ & $255(35.5)$ & \\
\hline Almost daily & $211(1.7)$ & $125(59.2)$ & $86(40.8)$ & \\
\hline Listening to radio & & 12520 & & \multirow{5}{*}{0.27} \\
\hline None & $9210(73.6)$ & $5571(60.5)$ & $3639(39.5)$ & \\
\hline Less than once a week & $1118(8.9)$ & $710(63.5)$ & $408(36.5)$ & \\
\hline At least once a week & $1141(9.1)$ & $692(60.6)$ & $449(39.4)$ & \\
\hline Almost daily & $1051(8.4)$ & $643(61.2)$ & $408(38.8)$ & \\
\hline Watching TV & & 12518 & & \multirow{5}{*}{0.02} \\
\hline None & $2398(19.2)$ & $1395(58.2)$ & $1003(41.8)$ & \\
\hline Less than once a week & $550(4.4)$ & $340(61.8)$ & $210(38.2)$ & \\
\hline At least once a week & $1461(11.7)$ & $907(62.1)$ & $554(37.9)$ & \\
\hline Almost daily & $8109(64.8)$ & $4973(61.3)$ & $3136(38.7)$ & \\
\hline Ever smoked & & 12519 & & \multirow{3}{*}{0.03} \\
\hline None & $11422(91.2)$ & $6981(61.1)$ & $4441(38.9)$ & \\
\hline Yes & $1097(8.8)$ & $635(57.9)$ & $462(42.1)$ & \\
\hline Ever drank alcohol & & 12519 & & \multirow{3}{*}{0.03} \\
\hline None & $2071(16.5)$ & $1217(58.8)$ & $854(41.2)$ & \\
\hline Yes & $10448(83.5)$ & $6398(61.2)$ & $4050(38.8)$ & \\
\hline
\end{tabular}

that these young women did not receive iron supplements during their pregnancy. Also, our study revealed that education was significantly associated with less risk of anemia among women who had postsecondary education compared to those who had no education. Several studies in different settings supported this finding [9, 31, 32].

Several environmental factors were found to be a positive risk of anemia. Unimproved sources of drinking water and unimproved toilet facility were about one time more likely to cause anemia as compared to the improved source of drinking water and sanitation facility. Naturally, arsenic enriched in groundwater had been found in tube well/hand pump drinking water supplies in Southeast Asia, including Lao PDR [33, 34], particularly in central and southern provinces of the country [35]. A previous study found an increased risk of anemia among women who had been exposed to arsenic from their drinking water [36, 37]. Although Lao PDR has made good progress in the provision of clean drinking water across the country, gaps still exist in rural villages [38], because $60 \%$ of the communities used dug wells as the main sources of water [39]. Moreover, Lao PDR had low rates of access to sanitation facilities in rural areas, where $73 \%$ of the population live [40]. Thus, we cannot neglect the probability of environmental contamination with parasites that causes anemia [41]. Therefore, interventions should strongly continue the provision of access to safe drinking water and improved sanitation facility in rural communities. Our findings were consistent with previous studies in other settings, including Myanmar [42], Nepal [6], Uganda [25], and Tanzania [26]. However, mass media exposure is a good source of receiving wider information, including health promotion programs, and increase chances of iron and folic acid supplements intake [43]. Our study showed that increasing the frequency of watching television is a significant protective factor against anemia in women; a similar finding was also found in India [44].

At the household level, geographic area of residence was found to be associated with anemia among women who lives in rural with road area and central and southern provinces who were one to two times more likely to be anemic, respectively. Similar associations between anemia and geographic location have been found in previous studies conducted in different settings of the same region [17, 27], and different region [6]. The southern provinces and some central provinces in Lao PDR are considered to be high malaria-endemic regions particularly in remote festered areas $[45,46]$. The majority of malaria infections were asymptomatic and half of them were associated with anemia in women [47]. Nevertheless, the reduction of malaria confirmed cases more than 50\% [48] and the high proportion of insecticide-treated bed nets coverage in endemic areas contributed to the reduction of malaria prevalence in Lao PDR [46, 49]; however, the effectiveness of treatment outcome for malaria by chloroquine, used as the first-line therapy for uncomplicated malaria and its resistance [50], and improper usage of insecticide-treated bed nets in rural areas during farming seasons [49] are a major challenge for malaria control in Lao PDR. Also, Schistosoma mekongi is an endemic parasite in a limited area of the southern province [51]. It is well documented that schistosomiasis infection is 
TABle 2: Associate factors with anemia among WRA in Lao PDR.

\begin{tabular}{|c|c|c|c|c|}
\hline \multirow{2}{*}{ Characteristics } & \multicolumn{2}{|c|}{ Crude } & \multicolumn{2}{|c|}{ Adjusted } \\
\hline & OR $(95 \% \mathrm{CI})$ & $p$-value & OR $(95 \% \mathrm{CI})$ & $p$-value \\
\hline \multicolumn{5}{|l|}{ Age, years } \\
\hline $15-24$ & Reference & & Reference & \\
\hline $25-34$ & $0.83(0.75-0.90)$ & $<0.001$ & $0.81(0.74-0.90)$ & $<0.001$ \\
\hline $35-49$ & $0.97(0.89-1.06)$ & 0.57 & $0.94(0.85-1.04)$ & 0.29 \\
\hline \multicolumn{5}{|l|}{ Education } \\
\hline None & Reference & & Reference & \\
\hline Primary & $0.85(0.76-0.95)$ & 0.005 & $0.89(0.78-1.00)$ & 0.06 \\
\hline Lower secondary & $0.87(0.77-0.98)$ & 0.02 & $0.91(0.79-1.05)$ & 0.21 \\
\hline Upper secondary & $0.87(0.76-0.99)$ & 0.04 & $0.91(0.77-1.07)$ & 0.26 \\
\hline Postsecondary/nontertiary & $0.73(0.58-0.91)$ & 0.006 & $0.76(0.60-0.97)$ & 0.03 \\
\hline Higher & $0.82(0.71-0.95)$ & 0.001 & $0.90(0.75-1.08)$ & 0.27 \\
\hline \multicolumn{5}{|l|}{ Ethnolinguistic } \\
\hline Lao-Tai & Reference & & Reference & \\
\hline Mon-Khmer & $0.97(0.89-1.06)$ & 0.51 & $0.94(0.82-1.08)$ & 0.45 \\
\hline Hmong-Mien & $0.52(0.45-0.60)$ & $<0.001$ & $0.48(0.39-0.59)$ & $<0.001$ \\
\hline Chinese-Tibetan & $0.80(0.63-1.02)$ & 0.07 & $1.23(0.94-1.61)$ & 0.11 \\
\hline Other & $1.18(0.82-1.71)$ & 0.35 & $0.97(0.66-1.41)$ & 0.87 \\
\hline \multicolumn{5}{|l|}{ Religion } \\
\hline Buddhist & Reference & & Reference & \\
\hline Animist & $0.82(0.75-0.88)$ & $<0.001$ & $1.04(0.91-1.19)$ & 0.49 \\
\hline Christian & $1.05(0.78-1.41)$ & 0.72 & $1.14(0.83-1.56)$ & 0.41 \\
\hline Other & $1.27(0.57-2.82)$ & 0.54 & $1.43(0.63-3.25)$ & 0.38 \\
\hline \multicolumn{5}{|l|}{ Area of residence } \\
\hline Urban & Reference & & Reference & \\
\hline Rural with road & $1.18(1.09-1.28)$ & $<0.001$ & $1.10(1.00-1.20)$ & 0.03 \\
\hline Rural without road & $0.92(0.80-1.05)$ & 0.24 & $0.90(0.77-1.05)$ & 0.21 \\
\hline \multicolumn{5}{|l|}{ Region of residence } \\
\hline Northern provinces & Reference & & Reference & \\
\hline Central provinces & $2.17(1.99-2.37)$ & $<0.001$ & $2.16(1.96-2.38)$ & $<0.001$ \\
\hline Southern provinces & $2.26(2.03-2.51)$ & $<0.001$ & $2.05(1.82-2.31)$ & $<0.001$ \\
\hline \multicolumn{5}{|l|}{ Size of family } \\
\hline$\leq 3$ persons & Reference & & Reference & \\
\hline $4-6$ persons & $1.06(0.96-1.18)$ & 0.19 & $1.08(0.97-1.20)$ & 0.12 \\
\hline$>6$ persons & $1.19(1.06-1.35)$ & 0.004 & $1.14(1.01-1.29)$ & 0.03 \\
\hline \multicolumn{5}{|l|}{ Source of drinking water } \\
\hline Improved & Reference & & Reference & \\
\hline Unimproved & $1.36(1.23-1.51)$ & $<0.001$ & $1.24(1.10-1.39)$ & $<0.001$ \\
\hline \multicolumn{5}{|l|}{ Type of toilet facility } \\
\hline Improved & Reference & & Reference & \\
\hline Unimproved & $1.36(1.25-1.48)$ & $<0.001$ & $1.15(1.03-1.28)$ & 0.01 \\
\hline \multicolumn{5}{|l|}{ Pregnancy status } \\
\hline None & Reference & & Reference & \\
\hline Current pregnant & $1.41(1.19-1.68)$ & $<0.001$ & $1.46(1.22-1.74)$ & $<0.001$ \\
\hline \multicolumn{5}{|l|}{ Adverse pregnancy outcomes } \\
\hline No (live births) & Reference & & Reference & \\
\hline Yes (stillbirths, miscarriage, abortion) & $1.19(1.08-1.30)$ & $<0.001$ & $1.14(1.03-1.25)$ & 0.008 \\
\hline \multicolumn{5}{|l|}{ Watching TV } \\
\hline None & Reference & & Reference & \\
\hline Less than once a week & $0.86(0.71-1.04)$ & 0.12 & $0.84(0.69-1.03)$ & 0.10 \\
\hline At least once a week & $0.85(0.74-0.97)$ & 0.01 & $0.80(0.69-0.92)$ & 0.003 \\
\hline Almost everyday & $0.87(0.80-0.96)$ & 0.006 & $0.84(0.75-0.95)$ & 0.005 \\
\hline \multicolumn{5}{|l|}{ Ever smoking } \\
\hline None & Reference & & Reference & \\
\hline Yes & $1.14(1.00-1.29)$ & 0.03 & $0.99(0.87-1.13)$ & 0.94 \\
\hline \multicolumn{5}{|l|}{ Ever drunk alcohol } \\
\hline None & Reference & & Reference & \\
\hline Yes & $0.90(0.82-0.99)$ & 0.03 & $0.92(0.83-1.03)$ & 0.18 \\
\hline
\end{tabular}


due to one of the parasites causing chronic blood loss, resulting in anemia $[52,53]$. Even though schistosomiasis was selected for elimination by WHO, reservoir animals and insufficient safe sources of water in the endemic area make a control strategy challenging [51]. Thus, the interventions should be considering the malaria control strategies to ensure the availability and propriety of insecticide-treated mosquito bed nets, and deworming programs in affected geographic areas should be prioritized.

Also, our study found that a large family size with more than 6 people was significantly associated with an increase in the risk of anemia. A similar outcome was found in a previous study conducted in Ethiopia [54]. This might be due to food insecurity and distribution for large family size. In addition, access to foods is another issue, especially in a rural area, because less than $2 \%$ have permanent markets available in rural villages and poor quality road infrastructure, particularly during the rainy season which makes access to foods more challenging [38]. Moreover, a recent study in Lao PDR reported a high prevalence of insufficient diversity of food consumption (90.1\%) and iron intake (61.8\%) among WRA [24]. However, a low risk of developing anemia was found among women who belonged to the Hmong-Mien ethnolinguistic group. Geographically, this ethnolinguistic group mostly live in mountainous areas of the northern part of the country [38]. Physiological hemoglobin demands are greater among people living at high altitudes due to the low concentration of oxygen in the atmosphere [12]. Thus, the hemoglobin increases with an increase of altitude which is reported in a study conducted in Peru [55], particularly when the altitude is above 1,000 meters above sea level [56]. A study in Myanmar reported lower odds of anemia among women who lived in the hilly zone compared to those living in another zone of the country [27].

Our study has some limitations. Due to the cross-sectional nature of the survey, it is not possible to analyze the cause-effect relationship between anemia and the predictor variables. Also, this study was not able to assess other risk factors for anemia such as the family history of thalassemia, parasitic infections, contraceptive use, nutritional status, and micronutrient deficiencies such as folate, iron, and B-12, which might have potentially an important impact on the development of anemia.

\section{Conclusions}

The anemia continues to be a major public health challenge in Lao PDR. The prevalence of anemia among WRA was high (39.2\%). Living in a rural area, in southern provinces, and with large family size, unimproved water and unimproved sanitation facility, being pregnant, and experiencing any adverse pregnancy outcomes were significantly associated to increase the risk of being anemia. Conversely, being aged 25-34 years and having postsecondary education and daily exposure to television were protective factors against anemia. Therefore, interventions should be considered on geographic variations, improving the provision of safe water and sanitation facilities, and promoting family planning and ANC by providing iron and acid folic supplements during pregnancy. Providing health education through mass media should be enhanced for women in rural areas.

\section{Data Availability}

The secondary data used in this analysis are available on reasonable request to the Lao Statistics Bureau, Ministry of Planning and Investment in Lao PDR. https://www.lsb.gov. la/en/home/

\section{Conflicts of Interest}

The authors declare that they have no conflicts of interest.

\section{Authors' Contributions}

S. Keokenchanh conceptualized and designed the study, analyzed the data, and wrote the manuscript. A. Morita advised for data analyses. S. Kounnavong advised for ethical review in Lao PDR. S. Kounnavong, A. Tokinobu, W. Ikeda, and K. Midorikawa contributed to the critical revision of the manuscript. S. Keokenchanh has the primary responsibility for the final content. All authors read and approved the final manuscript.

\section{Acknowledgments}

The authors would like to acknowledge the cabinet of the Ministry of Health of the Lao PDR for the overall communication support with the Lao Statistic Bureau, Ministry of Planning and Investment, for permission to use the dataset for this study. This study was supported by the Japanese Government Scholarship (MEXT).

\section{References}

[1] World Health Organization, Haemoglobin Concentrations for the Diagnosis of Anaemia and Assessment of Severity, World Health Organization, Geneva, Switzerland, 2011.

[2] World Health Organization, The Global Prevalence of Anaemia in 2011, WHO, Geneva, Switzerland, 2011.

[3] K. O. Osungbade and A. O. Oladunjoye, "Anaemia in developing countries: burden and prospects of prevention and control," in Anemia, pp. 116-129, IntechOpen, London, UK, 2012, http:// www.intechopen.com/books/anemia/anaemia-in-developingcountries-burden-and-\%20prospects-of-prevention-and-control.

[4] World Health Organization, Global Nutrition Targets 2025: Anaemia Policy Brief, WHO, Geneva, Switzerland, 2012, http://www.who.int//iris/bitstream/10665/148556/1/WHO_ NMH_NHD_14.4_eng.pdf.

[5] L. T. T. Trinh and M. Dibley, "Anaemia in pregnant, postpartum and non pregnant women in Lak District, Daklak Province of Vietnam," Asia Pacific Journal of Clinical Nutrition, vol. 16, pp. 310-315, 2007.

[6] S. Gautam, H. Min, H. Kim, and H. S. Jeong, "Determining factors for the prevalence of anemia in women of reproductive age in Nepal: evidence from recent national survey data," PLoS One, vol. 14, pp. 1-17, 2019.

[7] Y. Hu, M. Li, J. Wu et al., "Prevalence and risk factors for anemia in non-pregnant childbearing women from the Chinese fifth national health and nutrition survey," 
International Journal of Environmental Research and Public Health, vol. 16, 2019.

[8] E. O. Uche-Nwachi, A. Odekunle, S. Jacinto et al., "Anaemia in pregnancy: associations with parity, abortions and child spacing in primary healthcare clinic attendees in Trinidad and Tobago," African Health Sciences, vol. 10, pp. 66-70, 2010.

[9] M. Z. Siddiqui, S. Goli, T. Reja et al., "Prevalence of anemia and its determinants among pregnant, lactating, and nonpregnant nonlactating women in India," SAGE Open, vol. 7, pp. 1-10, 2017.

[10] A. Wemakor, "Prevalence and determinants of anaemia in pregnant women receiving antenatal care at a tertiary referral hospital in Northern Ghana," BMC Pregnancy and Childbirth, vol. 19, pp. 1-11, 2019.

[11] B. Benoist, E. McLean, I. Egli, and M. Cogswell, Worldwide Prevalence of Anaemia 1993-2005. WHO Global Database on Anemia, WHO, Geneva, Switzerland, 2008, http://whqlibdoc. who.int/publications/2008/9789241596657_eng.pdf.

[12] G. A. Stevens, M. M. Finucane, L. M. De-Regil et al., "Global, regional, and national trends in haemoglobin concentration and prevalence of total and severe anaemia in children and pregnant and non-pregnant women for 1995-2011: a systematic analysis of population-representative data," Lancet Global Health, vol. 1, pp. 16-25, 2013.

[13] World Health Organization, Weekly Iron and Folic Acid Supplementation Program for Women of Reproductive Age: An Analysis of Best Programme Practices, WHO, Geneva, Switzerland, 2011.

[14] S. Kounnavong, T. Sunahara, M. Hashizume et al., "Anemia and related factors in preschool children in the Southern Rural Lao people's democratic republic," Tropical Medicine and Health, vol. 39, no. 4, pp. 95-103, 2011.

[15] S. Inthavong, K. Sanchaisuriya, C. Chaninthorn, B. Phengdy, P. Sanchaisuriya, and G. F. S. Fucharoen, "Prevalence and risk factors for anemia and iron deficiency among female junior high school students in Vientiane, Lao people's democratic republic," Journal of Medical Technology and Physical Therapy, vol. 26, pp. 141-149, 2014.

[16] The United Nations in Lao PDR, "United Nations Lao PDRLao social indicator survey (LSIS II) 2017,” 2017, http://www. la.one.un.org/media-center/publications/430-lao-socialindicator-survey-lsis-ii-2017.

[17] P. H. Nguyen, K. C. Nguyen, B Le Mai et al., "Risk factors for anemia in Vietnam," The Southeast Asian Journal of Tropical Medicine and Public Health, vol. 37, no. 6, pp. 1213-1223, 2006.

[18] C. V. Charles, C. E. Dewey, A. Hall, C. Hak, S. Channary, and A. J. S. Summerlee, "Anemia in Cambodia: a cross-sectional study of anemia, socioeconomic status and other associated risk factors in rural women," Asia Pacific Journal of Clinical Nutrition, vol. 24, pp. 253-259, 2015.

[19] S. Ali, U. Khan, and A. Feroz, "Prevalence and determinants of anemia among women of reproductive age in developing countries," Journal of the College of Physicians and Surgeons Pakistan, vol. 30, no. 2, pp. 177-186, 2020.

[20] T. Mahmood, A. U. Rehman, G. Tserenpil et al., "The association between iron-deficiency anemia and adverse pregnancy outcomes: a retrospective report from Pakistan," Cureus, vol. 11, no. 10, p. e5854, 2019.

[21] B. Berhe, F. Mardu, H. Legese et al., "Prevalence of anemia and associated factors among pregnant women in Adigrat general hospital, Tigrai, Northern Ethiopia, 2018," BMC Research Notes, vol. 12, no. 1, pp. 1-6, 2019.

[22] E. A. Symington, J. Baumgartner, L. Malan et al., "Maternal iron-deficiency is associated with premature birth and higher birth weight despite routine antenatal iron supplementation in an urban South African setting: the NuPED prospective study," PLoS One, vol. 14, pp. 1-21, 2019.

[23] UNFPA in Lao PDR, Lao Social Indicator Survey (LSIS) 2011-12, UNFPA in Lao PDR, Vientiane, Laos, 2012, https:// lao.unfpa.org/en/resources/lao-social-indicator-survey-lsis2011-12.

[24] K. Ratsavong, T. Van Elsacker, D. Doungvichit, L. Siengsounthone, S. Kounnavong, and D. Essink, "Are dietary intake and nutritional status influenced by gender? the pattern of dietary intake in Lao PDR: a developing country," Nutrition Journal, vol. 19, pp. 1-16, 2020.

[25] O. Nankinga and D. Aguta, "Determinants of Anemia among women in Uganda: further analysis of the Uganda demographic and health surveys," BMC Public Health, vol. 19, 2019.

[26] C. Wilunda, S. Massawe, and C. Jackson, "Determinants of moderate-to-severe anaemia among women of reproductive age in Tanzania: analysis of data from the 2010 Tanzania demographic and health survey," Tropical Medicine \& International Health, vol. 18, no. 12, pp. 1488-1497, 2013.

[27] H. H. Win and M. K. Ko, "Geographical disparities and determinants of anaemia among women of reproductive age in Myanmar: analysis of the 2015-2016 Myanmar demographic and health survey. WHO South-East Asia," Journal of Public Health, vol. 7, pp. 107-113, 2018.

[28] P. Soma-Pillay, C. Nelson-Piercy, H. Tolppanen, and A. Mebazaa, "Physiological changes in pregnancy," Cardiovascular Journal of Africa, vol. 27, no. 2, pp. 89-94, 2016.

[29] Lao People's Revolutionary Youth Union, “Adolescent and youth situation analysis, Lao People's Democratic Republic: investing in young people is investing in the future," in Improving in Young People is Investing in the Future, pp. 1-125, Lao People's Revolutionary Youth Union, Vientiane, Laos, 2014, http://lao.unfpa.org/sites/default/ files/pub-pdf/Final_Eng_AYSA\%20Report.pdf.

[30] C. Manithip, A. Sihavong, K. Edin, R. Wahlstrom, and H. Wessel, "Factors associated with antenatal care utilization among rural women in Lao people's democratic republic," Maternal and Child Health Journal, vol. 15, no. 8, pp. 13561362, 2011.

[31] G. Stephen, M. Mgongo, T. Hussein Hashim, J. Katanga, B. Stray-Pedersen, and S. E. Msuya, "Anaemia in pregnancy: prevalence, risk factors, and adverse perinatal outcomes in Northern Tanzania," Anemia, vol. 2018, Article ID 1846280, 2018.

[32] Y. S. Balarajan, W. W. Fawzi, and S. V. Subramanian, "Changing patterns of social inequalities in anaemia among women in India: cross-sectional study using nationally representative data," BMJ Open, vol. 3, no. 3, Article ID e002233, 2013.

[33] K. H. Cho, S. Sthiannopkao, Y. A. Pachepsky, K.-W. Kim, and J. H. Kim, "Prediction of contamination potential of groundwater arsenic in Cambodia, Laos, and Thailand using artificial neural network," Water Research, vol. 45, no. 17, pp. 5535-5544, 2011.

[34] K.-W. Kim, P. Chanpiwat, H. T. Hanh, K. Phan, and S. Sthiannopkao, "Arsenic geochemistry of groundwater in Southeast Asia," Frontiers of Medicine, vol. 5, no. 4, pp. 420-433, 2011.

[35] P. Chanpiwat, S. Sthiannopkao, K. H. Cho et al., "Contamination by arsenic and other trace elements of tube-well water along the Mekong River in Lao PDR," Environmental Pollution, vol. 159, no. 2, pp. 567-576, 2011. 
[36] C. Hopenhayn, H. M. Bush, A. Bingcang, and I. Hertz-Picciotto, "Association between arsenic exposure from drinking water and anemia during pregnancy," Journal of Occupational and Environmental Medicine, vol. 48, no. 6, pp. 635-643, 2006.

[37] S. Surdu, M. S. Bloom, I. A. Neamtiu et al., "Consumption of arsenic-contaminated drinking water and anemia among pregnant and non-pregnant women in Northwestern Romania," Environmental Research, vol. 140, pp. 657-660, 2015.

[38] World Food Programme, Food and Nutrition Security Atlas of Lao PDR, World Food Programme, Rome, Italy, 2013, https:// reliefweb.int/report/lao-peoples-democratic-republic/food-andnutrition-security-atlas-lao-pdr-september-2013.

[39] T. Fengthong, S. Dethoudom, and O. Keosavanh, Drinking Water Quality in the Lao People's Democratic Republic, ESCAP-IWMI Seminar on Environmental and Public Health Risks Due to Contamination of Soils, Crops, Surface and Groundwater from Urban, Industrial and Natural Sources in South East Asia, Hanoi, Vietnam, 2002.

[40] The World Bank, Report No. ACS12445: Lao People's Democratic Republic Strengthening Water Supply, Sanitation and Hygiene Sector Coordination in Lao PDR Supporting Sector Reform for Scaling up Rural Sanitation-Synthesis Report, The World Bank, Washington, DC, USA, 2015, http://documents1. worldbank.org/curated/pt/295871468047763941/pdf/Lao-PDRSanitation-Synthesis-Report-P132249-final.pdf.

[41] S. C. K. Tay, E. A. Nani, and W. Walana, "Parasitic infections and maternal anaemia among expectant mothers in the Dangme East District of Ghana," BMC Research Notes, vol. 10, pp. 1-9, 2017.

[42] A. Zhao, H. Gao, Y. Zhang et al., "Prevalence of anemia and its risk factors among lactating mothers in Myanmar," The American Journal of Tropical Medicine and Hygiene, vol. 90, no. 5, pp. 963-967, 2014.

[43] A. Chourasia, C. M. Pandey, and A. Awasthi, "Factors influencing the consumption of iron and folic acid supplementations in high focus states of India," Clinical Epidemiology and Global Health, vol. 5, no. 4, pp. 180-184, 2017.

[44] V. Perumal, "Reproductive risk factors assessment for anaemia among pregnant women in India using a multinomial logistic regression model," Tropical Medicine \& International Health, vol. 19, no. 7, pp. 841-851, 2014.

[45] P. Vilay, D. Nonaka, P. Senamonty et al., "Malaria prevalence, knowledge, perception, preventive and treatment behavior among military in Champasak and Attapeu Provinces, Lao PDR: a mixed methods study," Tropical Medicine and Health, vol. 47, pp. 1-12, 2019.

[46] J. Kobayashi, S. Phompida, T. Toma, S. Looareensuwan, H. Toma, and I. Miyagi, "The effectiveness of impregnated bed net in malaria control in Laos," Acta Tropica, vol. 89, no. 3, pp. 299-308, 2004.

[47] V. Briand, J. Y. Le Hesran, M. Mayxay et al., "Prevalence of malaria in pregnancy in Southern Laos: a cross-sectional survey," Malaria Journal, vol. 15, pp. 1-11, 2016.

[48] World Health Organization, WHO Global Malaria Programme: World Malaria Report 2010, World Health Organization, Geneva, Switzerland, 2010, https://www.who.int/malaria/world_ malaria_report_2010/worldmalariareport2010.pdf.

[49] D. Nonaka, S. Laimanivong, J. Kobayashi et al., "Is staying overnight in a farming hut a risk factor for malaria infection in a setting with insecticide-treated bed nets in rural Laos?" Malaria Journal, vol. 9, no. 1, p. 372, 2010.

[50] D. R. Pillai, A. C. Labbé, V. Vanisaveth et al., "Plasmodium falciparum Malaria in Laos: chloroquine treatment outcome and predictive value of molecular markers," The Journal of Infectious Diseases, vol. 183, no. 5, pp. 789-795, 2001.

[51] V. Khieu, S. Sayasone, S. Muth et al., "Elimination of schistosomiasis mekongi from endemic areas in Cambodia and the Lao people's democratic republic: current status and plans," Tropical Medicine and Infectious Disease, vol. 4, pp. 1-15, 2019.

[52] Z. Farid, V. N. Patwardhan, and W. J. Darby, "Parasitism and anemia," The American Journal of Clinical Nutrition, vol. 22, no. 4, pp. 498-503, 1969.

[53] N. M. Nour, "Schistosomiasis: health effects on women," Reviews in Obstetrics and Gynecology, vol. 3, pp. 28-32, 2010.

[54] A. Bekele, M. Tilahun, and A. Mekuria, "Prevalence of anemia and its associated factors among pregnant women attending antenatal care in health institutions of Arba Minch town, Gamo Gofa zone, Ethiopia: a cross-sectional study," Anemia, vol. 2016, Article ID 1073192, 2016.

[55] G. F. Gonzales, V. Tapia, and A. L. Fort, "Maternal and perinatal outcomes in second hemoglobin measurement in nonanemic women at first booking: effect of altitude of residence in Peru," ISRN Obstetrics and Gynecology, vol. 2012, Article ID 368571, 7 pages, 2012.

[56] Y. Xing, H. Yan, S. Dang, B. Zhuoma, X. Zhou, and D. Wang, "Hemoglobin levels and anemia evaluation during pregnancy in the highlands of Tibet: a hospital-based study," BMC Public Health, vol. 9, pp. 1-7, 2009. 